\title{
Overstaging: A Challenge in Rectal Cancer Treatment
} \author{
Marko Kornmann ${ }^{a}$ \\ ${ }^{a}$ Clinic of General, Visceral, and Transplantion Surgery, University of UIm, UIm, Germany; \\ ${ }^{b}$ Clinic of Diagnostic and Interventional Radiology, University of Ulm, Ulm, Germany
}

Jan Scheele $^{a}$ Stefan Andreas Schmidt ${ }^{b}$ Sandra Tenzer ${ }^{a}$ Doris Henne-Bruns ${ }^{a}$

\section{Keywords}

Rectal cancer - Staging - Endoscopic ultrasound, EUS .

Computed tomography, CT .

Magnetic resonance imaging, MRI

\section{Summary}

Background: Preoperative staging, including computed tomography (CT), magnetic resonance imaging (MRI), and endoscopic ultrasound (EUS), is decisive to envisage the therapeutic concept for rectal cancer (RC). Overstaging may subject the patient to neoadjuvant therapy that does not improve survival but may lead to therapyassociated morbidity. Methods: This study retrospectively compares and values EUS, CT, and MRI in Union Internationale Contre le Cancer (UICC) stage I-III RC with a focus on overstaging. RC patients receiving primary operation only at the University Clinic UIm were analyzed. The therapeutic relevance of preoperative staging was determined by comparison with postoperative pathological workup. Results: 244 examinations in $184 \mathrm{RC}$ patients (EUS: $n=63, C T: n=143, M R I: n=38$ ) revealed therapy-relevant overstaging into the T3/4 category in 10 (16\%) EUS, 18 (13\%) CT, and 10 (26\%) MRI cases. Patients were upgraded to the $\mathrm{N}+$ category in $13(21 \%)$ EUS, $29(20 \%) \mathrm{CT}$, and $11(29 \%) \mathrm{MRI}$ cases. As a result, UICC stages II and III turned out to be overstaged in 13 (21\%) EUS, $18(13 \%)$ CT, and 10 (26\%) MRI cases. Conclusion: More than $10 \%$ therapy-relevant overstaging by any method represents a major challenge for modern RC therapy. Physicians should scrupulously consider this fact in their treatment considerations to avoid overtreatment.

(C) 2018 S. Karger GmbH, Freiburg

\section{Introduction}

Rectal cancer (RC) is one of the most common malignancies in Western countries [1]. Its incidence is still slightly increasing in some areas including Germany on account of demographic changes and nutrition habits [2]. In contrast, there has been a decline in mortality over the past 3 decades due to earlier detection, operative technique, and multimodal therapy [3].

While therapeutic choices have been constantly increasing, staging of RC relies on three different staging modalities: endoscopic ultrasound (EUS), computed tomography (CT), and magnetic resonance imaging (MRI). EUS and MRI show comparable high accuracy levels for T (EUS: 63-95\%, MRI: 65-86\%) and N (EUS: $64-84 \%$, MRI: 85-97\%) according to Union Internationale Contre le Cancer (UICC) [4-6]. Multidetector CT (MDCT) can be highly accurate in T, N, and UICC staging $(86,84$, and $89 \%)$, too [7]. However, all modalities are at risk of staging failure. Overstaging is reported in up to $30 \%$ regardless of the modality used $[3,8]$.

Pretherapeutic staging is essential to determine the therapeutic concept for RC, mainly consisting of primary surgery only or neoadjuvant (chemo-)radiation therapy (NRT) with curative intent. T and $\mathrm{N}$ status strongly correlate with prognosis and local recurrence rates. However, each UICC stage is heterogeneously structured, including patients with good, intermediate, and poor prognosis. This is most distinctive in the case of UICC II and III tumors, which are found in up to $80 \%$ in daily clinical practice. With respect to tumor location (high: $12-16 \mathrm{~cm}$, middle: $6-12 \mathrm{~cm}$, low: $0-6 \mathrm{~cm}$ from the anocutaneous line (ACL)), discrimination between $\mathrm{T} 1 / 2$ and $\mathrm{T} 3 / 4$ status as well as detection of lymph node involvement $(\mathrm{N}+)$ is crucial to schedule the therapeutic concept. Based on several multicenter trials the concept of NRT followed by total mesorectal excision (TME) has become the treatment of choice for middle and low RC UICC stage II (T3-4 N0) and III (T1-4 N+) [9, 10]. It has demonstrated significantly better local tumor control and at least bisection of local recurrence rates in those patients with poor prognosis (T3, N+, deep extramural invasion). However, preoperative NRT

\section{KARGER}

() 2018 S. Karger GmbH, Freiburg

Fax +497614520714
Prof. Dr. med. Marko Kornmann

Clinic of General and Visceral Surgery University of Ulm

Albert-Einstein-Allee 23, 89081 Ulm, Germany marko.kornmann @ uniklinik-ulm.de 
does not improve overall survival versus postoperative chemoradiation and may be harmful to those who do not require extensive pretreatment (intermediate prognosis: T1-2 N1, T3 N0) or even patients sufficiently treated by surgery alone (good prognosis: T1-2 N0) [11]. Furthermore, NRT does not guarantee local cure. The rate of patients who develop a local recurrence despite NRT is at least $6 \%$ [12]. Further criteria such as the circumferential resection margin (CRM), depth of extramural invasion, and extramural vascular invasion have been identified which proved to provide even better prognostic value and resulted in a subdivision outside of the UICC classification [13]. Although these variables are continuously implemented into the actual guidelines, they have not yet fully reached daily clinical practice. The revision of the Dutch RC guidelines 2012, published in 2014, has led to a reduction of NRT in T3 N0 tumors of $31.6 \%$ [14]. Hence, overstaging is critical to obtain oncological benefits of NRT in a more selected group of patients.

In addition to prognostic implications, there is a rising debate about the drawbacks of multimodal therapy regarding functional outcome and quality of life (QoL). $50-90 \%$ of RC patients experience some form of bowel dysfunction following anterior resection (AR) [15-17]. The low anterior resection syndrome (LARS) comprises symptoms like urgency, incontinence, frequent bowel movement, and clustering that may persist and thus impair long-term QoL after AR. In a recent study, we found LARS to be substantially worsened by radiation [18]. Independent of the protocol of the pretreatment used (short-term $5 \times 5$ Gy, long-term radiochemotherapy), these patients have significantly more bowel movements per day and especially during the night. An extensive rate of long-term fecal incontinence further highlights the lifelong price to pay [19]. In this regard, overstaging should be accepted as a determinant. Overstaging subjects the patient to unnecessary RT and impaired QoL.

With growing evidence for a rational use of radiochemotherapy in $\mathrm{RC}$, the requirements for accurate staging are considerably increasing to balance oncologic results and QoL. In this controversy, stage-related overstaging has not been explicitly addressed as a primary issue so far. Therefore, we aimed our study to retrospectively compare and assess overstaging by EUS, CT, and MRI for UICC stage I-III RC patients with primary operation and without NRT.

\section{Patients and Methods}

\section{Design}

In this retrospective analysis, we evaluated the accuracy of three different imaging modalities in local staging for RC. CT, MRI, and EUS were compared regarding sensitivity and specificity, stage-related accuracy, and risk of therapyrelevant overstaging.

To meet our concern, we intentionally chose a period from 2002 until 2008 when neoadjuvant pretreatment was not yet extensively/routinely established at our clinic for all UICC II/III RC patients. Alternatively, a substantial proportion of patients received adjuvant treatment. This enabled us with the possibility to compare high-quality preoperative staging with complete pathological workup, but without the diagnostic alterations caused by NRT. Due to the fact that modern imaging still lacks precise response criteria to allow for differentiation between vital tumor mass and the desired downsizing/downstaging effects like tumor necrosis/edema/fibrosis, only those patients receiving primary operation were subject to statistical analysis.

\section{Participants}

All consecutive RC patients UICC stage I-III treated between 2002 and 2008 at the University Clinic Ulm were identified using our tumor documentation system, i.e. Cancer REtrieval and DOcumentation System - CREDOS 2. Informed consent was obtained for each participant. Postoperative pTN status and availability of at least one of the three pretherapeutic imaging modalities were mandatory for inclusion. Patients diagnosed with invasive cancer on primary endoscopic polypectomy were excluded due to alterations in secondary staging. Missing data, unavailable local staging, and no surgery for various reasons (refusal, inoperability for anesthesiological reasons, endoscopic local therapy) were also criteria for exclusion. According to treatment strategy, RC patients were subdivided into a primary operation group and neoadjuvant treatment groups with or without restaging. As mentioned above, patients with NRT were excluded.

For each patient, age, gender, tumor site, modalities of staging, therapy, body mass index (BMI), and pre- and postoperative tumor stage according to UICC staging manual version 6.0 were recorded from the internal database. For simplification matters, preoperative staging results were illustrated by the prefix 'c' for all modalities. The tumor site was characterized into low, middle, or high based on the distance of the lower tumor margin to the ACL. Detailed information was provided on the therapy of each patient, i.e. curative/palliative or adjuvant/neoadjuvant, as well as the operative procedure (sphincter-preserving AR, abdominoperineal resection, or transanal tumor resection).

\section{Statistical Analysis}

Sensitivity, specificity, and accuracy of CT, MRI, and EUS were evaluated using the chi-square test. The different $\mathrm{T}$ stages and $\mathrm{N}$ stages were analyzed separately. The nodal status was set $\mathrm{N}+$ for $\mathrm{N} 1$ and $\mathrm{N} 2$ since the number of pathologic lymph nodes is not decisive for the treatment strategy in RC. In case the applied imaging modality could not define T/N stage precisely, e.g. for motion artefacts in CT/MRI or incomplete EUS due to tumor stenosis, the terms TX and NX were used. In case of imprecise statements such as T2-3, the lower value was recorded.

Dichotomous analysis of $\mathrm{T}$ stages was performed to assess imaging results according to their therapeutic relevance. T1/2 as well as T3/4 status were therefore combined. In case of TX and/or NX, the more favorable UICC stage was assumed.

\section{Results}

\section{Patient Characteristics}

219 (62.4\%) out of 351 RC patients were evaluable by fulfillment of the inclusion criteria for primary RC surgery with complete pathological workup. 58 patients with incomplete external documentation on pTNM and/or local staging, 36 patients receiving abdominal ultrasound exclusively, 1 patient undergoing emergency operation for intestinal obstruction without preoperative staging, and 30 patients without operation (25 technical inoperability, 1 inoperability for anesthesiological reasons, and 4 refusal of operation) were excluded from the study. Another 7 patients were excluded due to primary endoscopic polypectomy. Figure 1 outlines the reasons for failure of study enrollment for 132 patients.

\section{Evaluation of Staging}

$184(84.9 \%)$ out of 219 patients underwent primary operation, thus qualifying for statistical analysis. At a total count of 244, the mean number of local staging examinations was 1.3 . The majority 


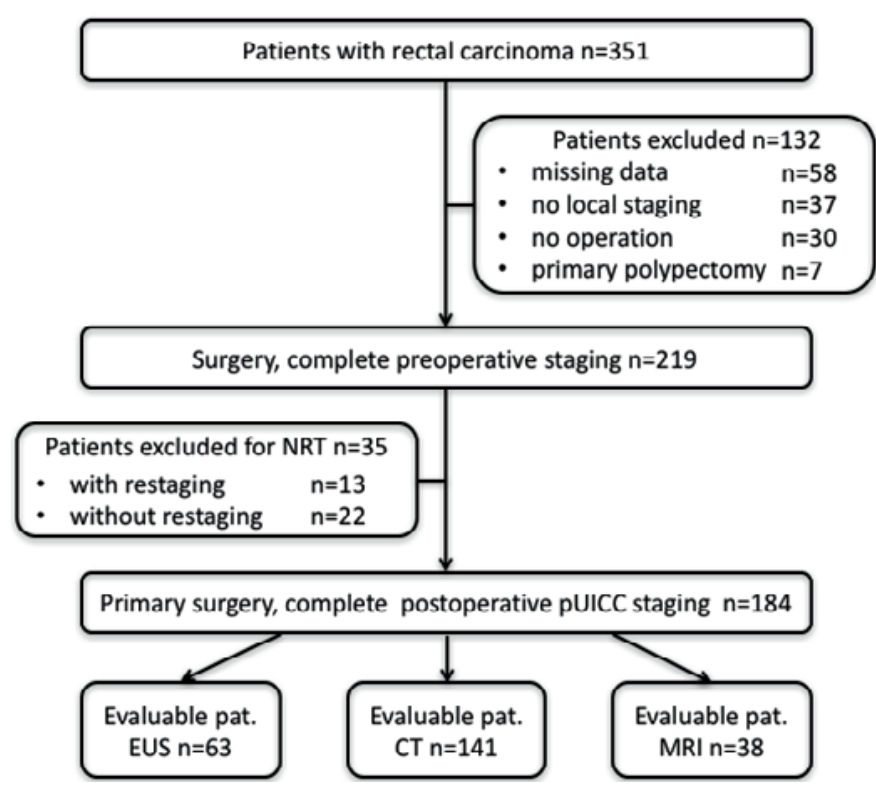

Fig. 1. Study enrollment of 351 consecutive patients (2002-2008) with rectal cancer. Due to multiple staging by different modalities the number of examinations is higher than the total number of patients included for analysis.

of examinations was performed at the University Clinic Ulm (EUS: 94\%, CT: 72\%, MRI 87\%), the lesser part accounting for external institutions (EUS: 6\%, CT: 28\%, MRI: 13\%). 15 different investigators were recorded for EUS examinations and 6 for CT scans and MRI. 35 (15.9\%) patients received neoadjuvant treatment with $(\mathrm{n}=$ $13)$ or without $(n=22)$ restaging. In $35 \%(n=63)$ the tumor was localized in the lower rectum $(<6 \mathrm{~cm}$ from ACL), in $48 \%(\mathrm{n}=88)$ in the middle rectum $(6-12 \mathrm{~cm}$ from ACL), and in $17 \%(\mathrm{n}=31)$ in the upper rectum $(12-16 \mathrm{~cm}$ from ACL).

\section{Staging Results}

Table 1 outlines pre- and postoperative staging results by imaging group. Regarding the three different imaging modalities, EUS was applied in 63 patients (UICC I: $n=20$, UICC II: $n=14$, UICC III: $\mathrm{n}=29$ ), CT in 143 patients (UICC I: $\mathrm{n}=35$, UICC II: $\mathrm{n}=34$, UICC III: $\mathrm{n}=74$ ), and MRI in 38 patients (UICC I: $\mathrm{n}=15$, UICC II: $\mathrm{n}=5$, UICC III: $\mathrm{n}=18$ ) patients. The male/female ratio was 1 : 0.5 for EUS, 1: 0.75 for CT, and 1:1 for MRI. Median age (EUS: 64 years, CT: 65 years, MRI: 64 years) and BMI (EUS: $25.8 \mathrm{~kg} / \mathrm{m}^{2}$, CT: $26 \mathrm{~kg} / \mathrm{m}^{2}$, MRI: $26.4 \mathrm{~kg} / \mathrm{m}^{2}$ ) were equal in the three groups. For EUS, CT, and MRI, the correct T stage could not be determined in $2(3 \%), 36(36 \%)$, and $3(8 \%)$, respectively, which resulted in TX grouping. NX was determined in 11 (17\%) EUS, 24 (17\%) CT, and 6 (16\%) MRI examinations. Reasons for X-staging comprised motion artifacts in CT/MRI and incomplete passage by tumor obstruction using EUS. Referring to the underlying preoperative $\mathrm{cT}$ and cN findings, EUS revealed cUICC I in 8 (13\%) and cUICC II/ III in 55 (87\%). CT and MRI revealed cUICC I in 21 (15\%) and 2 (5\%) as well as cUICC II/III in $122(85 \%)$ and 36 (95\%), respectively. Upon histologic examination of the resection specimens, pUICC I was found in 21 (33\%, EUS group), 39 (27\%, CT group),
Table 1. Pre- and postoperative staging results by imaging group; the total number of patients is lower than the number of examinations due to the fact that some patients received multimodal staging

\begin{tabular}{|c|c|c|c|c|}
\hline & \multirow[t]{2}{*}{ Patients } & \multicolumn{3}{|c|}{ Examinations } \\
\hline & & EUS & CT & MRI \\
\hline $\mathrm{n}$ & 184 & 63 & 143 & 38 \\
\hline \multicolumn{5}{|l|}{ Gender } \\
\hline Male & $119(65 \%)$ & $41(65 \%)$ & $87(59 \%)$ & $20(53 \%)$ \\
\hline Female & $65(35 \%)$ & $22(35 \%)$ & $56(39 \%)$ & $18(47 \%)$ \\
\hline $\begin{array}{l}\text { Age, median, } \\
\text { years }\end{array}$ & 64.5 & 64 & 65 & 64 \\
\hline $\begin{array}{l}\text { BMI, median, } \\
\mathrm{kg} / \mathrm{m}^{2}\end{array}$ & 25.7 & 25.8 & 26 & 26.4 \\
\hline \multicolumn{5}{|l|}{ TNM classification } \\
\hline cT1/cT2 & $52(28 \%)$ & $25(40 \%)$ & $33(23 \%)$ & $8(21 \%)$ \\
\hline cT3/cT4 & $103(56 \%)$ & $36(57 \%)$ & $59(41 \%)$ & $27(71 \%)$ \\
\hline cTx & $29(16 \%)$ & $2(3 \%)$ & $51(36 \%)$ & $3(8 \%)$ \\
\hline cNo & $57(31 \%)$ & $24(38 \%)$ & $52(36 \%)$ & $7(18 \%)$ \\
\hline $\mathrm{cN}+$ & $96(52 \%)$ & $28(44 \%)$ & $67(47 \%)$ & $25(66 \%)$ \\
\hline $\mathrm{cNx}$ & $31(17 \%)$ & $11(18 \%)$ & $24(17 \%)$ & $6(16 \%)$ \\
\hline $\mathrm{pT} 1 / \mathrm{pT} 2$ & $69(37 \%)$ & $27(43 \%)$ & $47(33 \%)$ & $18(47 \%)$ \\
\hline $\mathrm{pT} 3 / \mathrm{pT} 4$ & $115(63 \%)$ & $36(57 \%)$ & $96(67 \%)$ & $20(53 \%)$ \\
\hline $\mathrm{pTx}$ & - & - & - & - \\
\hline pN0 & $92(50 \%)$ & $34(54 \%)$ & $69(48 \%)$ & $20(53 \%)$ \\
\hline $\mathrm{pN}+$ & $92(50 \%)$ & $29(46 \%)$ & $74(52 \%)$ & $18(47 \%)$ \\
\hline $\mathrm{pNx}$ & - & - & - & - \\
\hline \multicolumn{5}{|l|}{ UICC stage } \\
\hline cUICC I & $22(12 \%)$ & $8(13 \%)$ & $21(15 \%)$ & $2(5 \%)$ \\
\hline cUICC II/III & $161(88 \%)$ & $55(87 \%)$ & $122(85 \%)$ & $36(95 \%)$ \\
\hline cUICC $\mathrm{x}$ & - & - & - & - \\
\hline pUICC I & $52(28 \%)$ & $21(33 \%)$ & $39(27 \%)$ & $12(19 \%)$ \\
\hline pUICC II/III & $132(72 \%)$ & $42(67 \%)$ & $104(73 \%)$ & $26(81 \%)$ \\
\hline
\end{tabular}

EUS = Endoscopic ultrasound; CT = computed tomography; MRI = magnetic resonance imaging; UICC $=$ Union Internationale Contre le Cancer; BMI = body mass index.

and 12 (19\%, MRI group) cases. pUICC II/III was correspondingly diagnosed in 42 (67\%), 104 (73\%), and 26 (81\%) cases.

\section{Sensitivity, Specificity and Accuracy}

MRI revealed the highest sensitivity in discriminating between T1/2 and T3/4 tumors (89\%) compared to EUS (76\%) and CT (66\%). Specificity was relatively low except for EUS (EUS: 63\%, CT: $40 \%$, MRI: $38 \%$ ), resulting in an accuracy of $70 \%$ for EUS, $58 \%$ for $\mathrm{CT}$, and $66 \%$ for MRI. Concerning N+ status, EUS, CT, and MRI revealed a sensitivity of 52,51 , and $78 \%$, respectively. Specificity for + status was found to be $62 \%$ for EUS, $58 \%$ for CT, and $45 \%$ for MRI. Accuracy was 57\% (EUS), 55\% (CT), and 61\% (MRI).

\section{Overstaging}

Based on the above-mentioned results, overstaging was present in all three imaging modalities. Regarding EUS, T-overstaging was 
found in 19 cases (30\%) and $\mathrm{N}$-overstaging in 13 cases (21\%). CT and MRI revealed overstaging of the T category in $20 \%(\mathrm{n}=29)$ and $34 \%(n=13)$ as well as of the N category in $20 \%(n=29)$ and $29 \%(n=11)$, respectively.

Comparison of $\mathrm{T} 1 / 2$ versus $\mathrm{T} 3 / 4$ revealed therapy-relevant overstaging to the T3 + 4 category by EUS, CT, and MRI in 10 (16\%), 18 (13\%), and 10 (26\%) cases, respectively. 13 (21\%) EUS, 29 (20\%) CT, and 11 (29\%) MRI cases were wrongly assigned to the $\mathrm{N}+$ category. As a result, UICC stages II and III were found to be overstaged in 13 (21\%), 18 (13\%), and 10 (26\%) of EUS, CT, and MRI cases, respectively (table 2).

\section{Discussion}

All cancer staging goes along with the potential risk of staging failure. Regarding RC, this may subject the patient to either undertreatment or overtreatment. While undertreatment could adversely affect oncologic outcome in terms of local recurrence upon detention of neoadjuvant therapy, overtreatment might impair postoperative functional outcome in terms of QoL due to unnecessary NRT. In a recent study, we stated that especially those patients receiving NRT were at high risk to develop major LARS [18]. Moreover, RC patients are more likely to die from distant metastatic disease than local recurrence today. Therefore, the oncologic advantages of NRT should be balanced with radiotherapy-related morbidity.

A rising number of therapeutic choices for $\mathrm{RC}$ is accompanied by three different staging modalities: EUS, CT, and MRI. All these modalities have their benefits and specific limitations restricting overall performance. On the technical side, EUS is basically not applicable in tumors obstructing the rectal lumen as MRI is for patients carrying older pacemaker models. On the practical side, EUS proved to be highly accurate in early $\mathrm{T}$ stages but less so for advanced cancer, resulting in overall levels ranging from 63 to $95 \%$ [4-6]. Staging accuracy for nodal status has been reported to be 64-84\% [4]. CT is an essential part of the pretherapeutic workup. It marks the gold standard in the detection and characterization of distant metastasis but is limited in distinguishing different layers of pelvic anatomy, thus disqualifying it as the primary examination for local RC staging [20]. However, MDCT has demonstrated high accuracy in T, N and UICC staging $(86,84$, and $89 \%$, respectively) except for UICC I [7]. Furthermore, CT is less dependent on availability and local expertise compared to EUS and MRI. MRI showed overall accuracies for T staging between 65 and 86\% [5]. Sensitivity and specificity of lymph node involvement was reported in up to 85 and $97 \%$, respectively [21]. MRI proved to be clearly superior to EUS and CT in depicting the mesorectal fascia and its relation to the tumor [22]. Regarding $\mathrm{T}$ status, our findings are quite in line with the literature since we found an overall accuracy for $\mathrm{T}$ status in 74\% (EUS), 72\% (CT), and 77\% (MRI). However, accuracy levels regarding the $\mathrm{N}$ status were substantially lower (EUS: $58 \%$, CT: 57\%, MRI: $61 \%)$. The difference is best explained by discrete implementation of technical progress into the clinical field. All imag-
Table 2. Therapy-relevant overstaging of three different imaging modalities; results itemized for $\mathrm{T} / \mathrm{N}$ status and summarized according to UICC

\begin{tabular}{llll}
\hline & EUS & CT & MRI \\
\hline $\mathrm{N}$ & 63 & 143 & 38 \\
\hline $\begin{array}{l}\text { Therapy-relevant overstaging } \\
\text { T3/4 category }\end{array}$ & $10(16 \%)$ & $18(13 \%)$ & $10(26 \%)$ \\
N+ category & $13(21 \%)$ & $29(20 \%)$ & $11(29 \%)$ \\
UICC II/III & $13(21 \%)$ & $18(13 \%)$ & $10(26 \%)$ \\
\hline
\end{tabular}

EUS = Endoscopic ultrasound $\mathrm{CT}=$ computed tomography; $\mathrm{MRI}=$ magnetic resonance imaging; UICC $=$ Union Internationale Contre le Cancer.

ing modalities have been subject to qualitative improvement over the last decade, with the most substantial one concerning MRI. In the requested period (2002-2008), 1.5 Tesla devices were used at the University Clinic Ulm. With currently 3 Tesla MRI, sensitivity, specificity, and accuracy are expected to be substantially higher. Moreover, we cannot exclude that MRI accuracy rates in clinical routine may be substantially lower than in selective studies, as demonstrated for other modalities as well [23]. In the present analysis, all examinations were carried out by a variety of internal and external investigators reflecting routine daily practice.

Overstaging of the $\mathrm{T}$ or $\mathrm{N}$ category does not inadvertently result in overtreatment. At first, UICC III tumors of the middle and lower rectum are commonly assigned to NRT whereas patients with a tumor located in the upper third of the rectum should be treated like colon cancer patients, i.e. undergo primary surgery [5]. Thus, overstaging was negligible for 31 (17\%) patients included in our analysis. Secondly, a false $\mathrm{T}>2$ or a false $\mathrm{N}+$ is not relevant for therapy when either of them correctly allows NRT. As expected, we found a difference between the isolated $\mathrm{T} / \mathrm{N}$ results and those transferred to UICC stages. However, with more than $10 \%$ in each imaging group (EUS, CT, MRI), therapy-relevant UICC overstaging turns out to be worth optimizing.

Our approach limits direct comparison with the literature, which is majorly focused on over-/understaging $\mathrm{T}$ and $\mathrm{N}$ separately. In most cases, available data are neither stage-related nor referred to their therapeutic relevance. Our report did not only focus on separate determination of $\mathrm{T}$ - and $\mathrm{N}$-overstaging but emphasized UICC stage-dependent overstaging which is actually the parameter for recommending neoadjuvant treatment or not. Our study revealed therapy-relevant overstaging regarding the UICC classification in 21\% (EUS), 13\% (CT), and 26\% (MRI). Overstaging of the $\mathrm{T}$ category was found to be therapeutically relevant in $16 \%$ (EUS), $13 \%$ (CT), and 26\% (MRI). The frequency of false-positive $\mathrm{N}+$ was $21 \%$ (EUS), $20 \%$ (CT), and 29\% (MRI). Owing to an unmatched technical progress, MRI results appear undervalued by now.

The most frequently used diagnostic tool for local RC staging is EUS. A meta-analysis of 5,039 patients from 42 institutions revealed a high accuracy of EUS, with sensitivity rates of $88 \%$ and specificity rates of up to $99 \%$ [24]. However, these results did not prove true in large multicenter studies reflecting daily clinical rou- 
tine outside dedicated centers. For EUS, Marusch et al. [25] reported a frequency of $17.3 \%$ for $\mathrm{T}$ overstaging, which is quite in line with our findings. Shapiro et al. [26] found UICC stage-related overstaging (UICC I $\rightarrow$ UICC II/III) in 32/95 patients (33\%). However, the overstaging rate for nodal involvement alone was only $6.3 \%[26]$.

In our analysis, CT revealed the lowest frequency of therapyrelevant overstaging (T1/2 $\rightarrow$ T3/4: 13\%, N0 $\rightarrow \mathrm{N}+: 20 \%$, UICC II $\rightarrow$ UICC III: $13 \%$ ). These findings were quite in line with a study conducted by Dinter et al. [27], which reported overstaging by Hydro-CT in 3/23 (13\%) patients. However, low accuracy in detecting T1/2 lesions and nodal staging posed significant restrictions [27]. More recent studies reported accuracies of up to $87 \%$ for T staging and $80 \%$ for $\mathrm{N}$ staging by MDCT with multiplanar reconstruction $[7,28,29]$. It should therefore not be underrated in local RC staging but reconsidered as a companion for EUS or MRI in questionable cases.

Followed by EUS, MRI showed the highest frequency of therapy-relevant overstaging in our analysis (T1/2 $\rightarrow$ T3/4: 26\%, N0 $\rightarrow$ N+: 29\%, UICC II $\rightarrow$ UICC III: $26 \%)$. Reports focusing on overstaging by MRI are exceptionally rare. Ucar et al. [30] found 8/30 patients (27\%) upgraded to T3 by MRI. All these cases were localized in the lower rectum. Karatag et al. [31] reported on 4/24 cases (20.8\%) overstaged into the T3 category by phase-array MRI. No overstaging of lymph node status was reported. Kocaman et al. [32] found overstaging in overall $8 / 50$ cases, with $4 / 15$ patients staged from T2 to T3/4 (26.7\%). In a prospective study comparing standard local TN classification and a modified Wong's classification, MRI overstaging was revealed to be therapy-relevant in 16/42 cases (38\%) [33]. The N category was not evaluated. Our results for MRI, at least concerning the local invasion of rectal carcinoma (T stage), proved widely consistent with the literature.

Besides the standard local $\mathrm{T} / \mathrm{N}$ classification, there is increasing evidence that the extent of extramural invasion of $\mathrm{T} 3$ tumors and especially their distance to the mesorectal fascia are highly predictable for local recurrence. The ability of MRI to clearly display the CRM favors MRI over EUS and CT. According to our findings, a combination of MRI and MDCT appears to be the most practical approach to provide both optimized oncologic and functional outcome/QoL.

Our analysis yields detailed information about the nature of UICC-related overstaging. However, there are limitations. Understaging was not assessed. In a former study, Guillem et al. [34] stated that the rate of understaging by EUS for CT3N0 was higher than that of overstaging. The authors concluded that patients should therefore continue receiving NRT [34]. In contrast, Liang et al. [35] stated that overstaging is common with EUS and can be attributed to learning curve, operator dependency, and technical shortcomings. For CT, Taylor et al. [36] found a general tendency for overstaging as well. Notwithstanding the impact of NRT on local recurrence rates, overstaging exposes the rising number of RC survivors to a lifetime of impaired QoL. From this point of view, the time period of our analysis does not detract from its value today. Overstaging is more relevant than ever.

\section{Conclusion}

Our analysis revealed UICC stage-dependent overstaging to be relevant for therapy in more than $10 \%$ of RC patients regardless of the modality used. Results may further catalyze a rational utilization of imaging methods to reduce overstaging and, thus, to improve QoL without affecting oncologic results.

\section{Disclosure Statement}

The authors state that they have no conflicts of interest.

\section{References}

1 Siegel R, DeSantis C, Jemal A: Cancer statistics, 2014. CA Cancer J Clin 2014;64:104-117.

2 German Centre for Cancer Registry Data (ZfKD), 2011. www.krebsdaten.de/Krebs/DE/Content/Krebsarten/ Darmkrebs/darmkrebs_node.html.

3 Kornmann M, Staib L, Wiegel T, Kron M, HenneBruns D, Link K-H, Formentini A; Study Group Oncology of Gastrointestinal Tumors (FOGT): Long-term results of 2 adjuvant trials reveal differences in chemosensitivity and the pattern of metastases between colon cancer and rectal cancer. Clin Colorectal Cancer 2013; 12:54-61.

4 Tan KK, Tsang CB: Staging of rectal cancer-technique and interpretation of evaluating rectal adenocarcinoma, uT1-4, N disease, 2D and 3D evaluation. Semin Colon Rectal Surg 2010;2:197-204.

5 Bipat S, Glas AS, Slors FJ, Zwinderman AH, Bossuyt PM, Stoker J: Rectal cancer: local staging and assessment of lymph node involvement with endoluminal US, CT, and MR imaging - a meta-analysis. Radiology 2004;232:773-783.
Mackay SG, Pager CK, Joseph D, Stewart PJ, Solomon MJ: Assessment of the accuracy of transrectal ultrasonography in anorectal neoplasia. Br J Surg 2003;90: 346-350.

7 Ahmetoğlu A, Cansu A, Baki D, Kul S, Cobanoğlu U, Alhan E, Ozdemir F: MDCT with multiplanar reconstruction in the preoperative local staging of rectal tumor. Abdom Imaging 2011;36:31-37.

${ }_{8}$ Kreis ME, Junginger T, Rödel C, Heinemann V, Nikolaou K, Mansmann U, Jauch KW: The optimult study concept - selective neoadjuvant chemoradiation therapy based on preoperative MRI (Article in German). Zentralbl Chir 2010;135:302-306.

9 Leitlinienprogramm Onkologie (Deutsche Krebsgesellschaft, Deutsche Krebshilfe, AWMF): S3-Leitlinie Kolorektales Karzinom, Kurzversion 1.1, 2014, AWMF Registrierungsnummer: 021-007OL. http://leitlinienprogramm-onkologie.de/Leitlinien.7.0.html.
0 Gérard JP, André T, Bibeau F, Conroy T, Legoux JL, Portier G, Bosset JF, Cadiot G, Bouché O, Bedenne L; Société Française de Chirurgie Digestive (SFCD), Société Française d'Endoscopie Digestive (SFED0), Société Française de Radiothérapie Oncologique (SFRO): Rectal cancer: French Intergroup clinical practice guidelines for diagnosis, treatments and follow-up (SNFGE, FFCD, GERCOR, UNICANCER, SFCD, SFED, SFRO). Dig Liver Dis 2017;49:359-367.

11 Gunderson LL, Callister M, Marschke R, Young-Fadok T, Heppell J, Efron J: Stratification of rectal cancer stage for selection of postoperative chemoradiotherapy: current status. Gastrointest Cancer Res 2008;2:25-33.

12 Sauer R, Liersch T, Merkel S, Fietkau R, Hohenberger W, Hess C, Becker H, Raab HR, Villanueva MT, Witzigmann H, Wittekind C, Beissbarth T, Rödel C: Preoperative versus postoperative chemoradiotherapy for locally advanced rectal cancer: results of the German CAO/ARO/AIO-94 randomized phase III trial after a median follow-up of 11 years. J Clin Oncol 2012;30: 1926-1933. 
13 Glynne-Jones R, Wyrwicz L, Tiret E, Brown G, Rödel C, Cervantes A, Arnold D; ESMO Guidelines Committee: Rectal cancer: ESMO Clinical Practice Guidelines for diagnosis, treatment and follow-up. Ann Oncol 2017;28:22-40.

14 Gietelink L, Wouters MWJM, Marijnen CAM, van Groningen J, van Leersum N, Beets-Tan RGH, Tollenaar RAEM, Tanis PJ; Dutch Surgical Colorectal Cancer Audit Group: Changes in nationwide use of preoperative radiotherapy for rectal cancer after revision of the national colorectal cancer guideline. Eur J Surg Oncol 2017;43:1297-1303.

15 Bryant CL, Lunniss PJ, Knowles CH, Thaha MA, Chan CL: Anterior resection syndrome. Lancet Oncol 2012; 13:403-408.

16 Emmertsen KJ, Laurberg S: Bowel dysfunction after treatment for rectal cancer. Acta Oncol 2008;47:9941003.

17 Andreyev HJ, Davidson SE, Gillespie C, Allum WH, Swarbrick E; British Society of Gastroenterology; Association of Colo-Proctology of Great Britain and Ireland; Association of Upper Gastrointestinal Surgeons; Faculty of Clinical Oncology Section of the Royal College of Radiologists: Practice guidance on the management of acute and chronic gastrointestinal problems arising as a result of treatment for cancer. Gut 2012;61:179-192.

18 Scheele J, Lemke J, Meier M, Sander S, Henne-Bruns D, Kornmann M: Quality of life after sphincter-preserving rectal cancer resection. Clin Colorectal Cancer 2015;14:33-40.

19 Loos M, Quentmeier P, Schuster T, Nitsche U, Gertler R, Keerl A, Kocher T, Friess H, Rosenberg R: Effect of preoperative radio(chemo)therapy on long-term functional outcome in rectal cancer patients: a systematic review and meta-analysis. Ann Surg Oncol 2013;20: 1816-1828.

20 Juchems MS, Ernst AS, Kornmann M, Barth TF, Kramer K, Brambs HJ, Aschoff AJ: Value of MDCT in preoperative local staging of rectal cancer for predicting the necessity for neoadjuvant radiochemotherapy. Rofo 2009;181:1168-1174.
21 Brown G, Richards CJ, Bourne MW, Newcombe RG, Radcliffe AG, Dallimore NS, Williams GT: Morphologic predictors of lymph node status in rectal cancer with use of high-spatial-resolution MR imaging with histopathologic comparison. Radiology 2003;227:371377.

22 Mathur P, Smith JJ, Ramsey C, Owen M, Thorpe A, Karim S, Burke C, Ramesh S, Dawson PM: Comparison of CT and MRI in the pre-operative staging of rectal adenocarcinoma and prediction of circumferential resection margin involvement by MRI. Colorectal Dis 2003;5:396-401.

23 Ptok H, Gastinger I, Lippert H: Local diagnostics for rectal cancer. What is realistic? Chirurg 2012;83:448451.

24 Puli SR, Bechtold ML, Reddy JB, Choudhary A, Antillon MR, Brugge WR: How good is endoscopic ultrasound in differentiating various $\mathrm{T}$ stages of rectal cancer? Meta-analysis and systematic review. Ann Surg Oncol 2009;16:254-265.

25 Marusch F, Ptok H, Sahm M, Schmidt U, Ridwelski K, Gastinger I, Lippert H: Endorectal ultrasound in rectal carcinoma - do the literature results really correspond to the realities of routine clinical care? Endoscopy 2011;43:425-431.

26 Shapiro R, Ahmed Ali U, Lavery IC, Kiran RP: Endorectal ultrasound does not reliably identify patients with uT3 rectal cancer who can avoid neoadjuvant chemoradiotherapy. Int J Colorectal Dis 2013;28:9931000 .

27 Dinter DJ, Hofheinz RD, Hartel M, Kaehler GF, Neff W, Diehl SJ: Preoperative staging of rectal tumors: comparison of endorectal ultrasound, hydro-CT, and high-resolution endorectal MRI. Onkologie 2008;31: 230-235.

28 Sinha R, Verma R, Rajesh A, Richards CJ: Diagnostic value of multidetector row $\mathrm{CT}$ in rectal cancer staging: comparison of multiplanar and axial images with histopathology. Clin Radiol 2006;61:924-931.
29 Filippone A, Ambrosini R, Fuschi M, Marinelli T, Genovesi D, Bonomo L: Preoperative T and N staging of colorectal cancer: accuracy of contrast-enhanced multi-detector row CT colonography - initial experience. Radiology 2004;231:83-90.

30 Uçar A, Obuz F, Sökmen S, Terzi C, Sağol O, Sarıoğlu $S$, Füzün M: Efficacy of high resolution magnetic resonance imaging in preoperative local staging of rectal cancer. Mol Imaging Radionucl Ther 2013;22:42-48.

31 Karatağ O, Karatağ GY, Özkurt H, Değirmenci HK, Avlanmış Ö, Başak M, Baykan A: The ability of phased-array MRI in preoperative staging of primary rectal cancer: correlation with histopathological results. Diagn Interv Radiol 2012;18:20-26.

32 Kocaman O, Baysal B, Şentürk H, İnce AT, Müslümanoğlu M, Kocakoç E, Arıcı S, Uysal Ö, Yıldız K, Türkdoğan K, Danalığlu A: Staging of rectal carcinoma: MDCT, MRI or EUS. Single center experience. Turk J Gastroenterol 2014;25:669-673.

33 Muñoz E, Granero-Castro P, Frasson M, Escartin J, Esclapez P, Campos S, Flor-Lorente B, Garcia-Granero E: Modified Wong's classification improves the accuracy of rectal cancer staging by endorectal ultrasound and MRI. Dis Colon Rectum 2013;56:1332-1338.

34 Guillem JG, Díaz-González JA, Minsky BD, Valentini V, Jeong SY, Rodriguez-Bigas MA, Coco C, Leon R, Hernandez-Lizoain JL, Aristu JJ, Riedel ER, Nitti D, Wong WD, Pucciarelli S: cT3N0 rectal cancer: potential overtreatment with preoperative chemoradiotherapy is warranted. J Clin Oncol 2008;26:368-373.

35 Liang TY, Anil G, Ang BW: Imaging paradigms in assessment of rectal carcinoma: loco-regional and distant staging. Cancer Imaging 2012;12:290-303.

36 Taylor A, Slater A, Mapstone N, Taylor S, Halligan S: Staging rectal cancer: MRI compared to MDCT. Abdom Imaging 2007;32:323-327. 